\title{
The Role of Healthy Lifestyle in Cardiovascular Disease Prevention
}

\author{
M. Vavro (Michal Vavro)1, Z. Bystricka (Zuzana Bystricka)2, L. Kollarova (Livia \\ Kollarova) ${ }^{2,3}$, M. Armaiova (Maria Armaiova) ${ }^{3}$
}

${ }^{1}$ Slovak Medical University, Bratislava, SK

Original Article

${ }^{2}$ St. Elisabeth University of Health and Social Sciences, Bratislava, SK

${ }^{3}$ University Hospital with Polyclinic, Nove Zamky, SK

\section{E-mail address:}

michal.vavroszu@gmail.com

\section{Reprint address:}

Michal Vavro

Slovak Medical University - Faculty of Nursing and Professional Health Studies

Limbova 12

83303 Bratislava, SK

Source: Clinical Social Work and Health Intervention

Pages: $58-63$

\section{Reviewers:}

Peter Marks - marks.peter@hotmail.com

Selvaraj Subramanian-doc.selvaraj@gmail.com

\section{Key words:}

Health. Healthy lifestyle. Prevention.

\section{Publisher:}

International Society of Applied Preventive Medicine i-gap
Volume: 9

Issue: 3

CSWHI 2018; 9(3): 58 - 63; DOI 10.22359/cswhi_9_2_07 @ 2018 Clinical Social Work and Health Intervention

\section{Abstract:}

Objectives: The aim of this study was to estimate men and women's adherence to healthy lifestyle and to compare which sex takes more interest in healthy lifestyle.

Methods: We conducted an analysis of the empirical data obtained through an anonymous questionnaire, which was completed by 95 participants. After processing and evaluating the gathered information, 
quantitative and qualitative analysis was performed and the data was subsequently summarized into the tables. The statistical evaluation was conducted using Student's T-Test. The survey was carried out at four outpatient general practitioners' clinics during seven weeks. The survey participants were patients aged between 30 and 55 years.

Results: Based on the survey results it can be concluded that participants have mature attitudes towards their health and sufficient information on cardiovascular disease (CVD) risk factors. Female participants are more interested in healthy lifestyle than male.

Conclusions: This survey attempts to raise public awareness of deficiencies in the knowledge they have about healthy lifestyle and an increased incidence of the CVD risk factors in the population.

\section{Introduction}

Every man has his place in the world, his mission, and every being lives in a particular way of life. The quality of our lives is determined by the strength of our personality, willpower, system of values, beliefs and personal life experiences. At present, a man is expected to take full responsibility for his life; to care for his body; to maintain physical and mental harmony in his life. We live in fast-moving times full of challenges and conflicts, and we are forgetting real life values, such as health, well-being and balanced life.

Cardiovascular disease is the most common cause of morbidity and mortality in Slovakia, and in most European countries. It is well-known that the incidence of lifestyle disease is a result of the long-term impact of lifestyle risk factors - the key interventional targets. A major goal in the fight against the disease is to change the public attitude to their own health and the way they live. Preventive measures aimed at timely detection of CVD risk factors play an indispensable roll in improving quality of life. Cardiovascular disease risk is currently a society-wide issue.

\section{Objectives}

The aim of this study was to estimate the adherence to healthy lifestyle by men and women and to compare which sex takes more interest in healthy lifestyle.

\section{Participants and observation methods}

95 participants (45 men, 50 women) aged 30 to 50 years with cardiovascular risk profile of the currently healthy population were included in the survey. For the purposes of the survey we used an anonymous, non-standardized questionnaire consisting of 26 questions. The questionnaire was placed in four outpatient clinics - two of which were in the city and two in a village. For the purposes of analysis we used descriptive statistics, while statistically significant dependence was examined using the Student t-test in SPSS software.

\section{Results}

The question targeted at comparing the level of knowledge men and women have about cardiovascular risk factors was answered as follows: up to $84 \%$ of men consider overweight and hypertension to be the main cardiovascular disease risk factors, smoking was the second most frequent answer (71\%); a long-term exposure to stress the third (58\%); last was 
hypercholesterolemia (56\%). Less severe risk factors are according to $49.5 \%$ of men lack of physical activity; unbalanced diet (31\%); excessive consumption of alcohol $(33 \%)$.

$86 \%$ of female respondents believe the most dangerous triggering factor is hypertension, overweight $(78 \%)$ and smoking (68\%). Other CVD risk factors include, according to $64 \%$ of women, the lack of physical activity and long-term exposure to stress (66\%), followed by high cholesterol (60\%). An unbalanced diet is considered a minor risk factor by $34 \%$ of men and women. Excessive consumption of alcoholic beverages was marked as CVD risk factor by 18 women $(36 \%)$ (Table 1$)$.

Table 1: Risk factors for cardiovascular disease

\begin{tabular}{|l|c|c|c|c|}
\hline & \multicolumn{2}{|c|}{ Men } & \multicolumn{2}{c|}{ Women } \\
\hline Reply & n & \% & n & $\%$ \\
\hline Increased cholesterol & 25 & 56,00 & 30 & 60,00 \\
\hline Lack of physical activity & 22 & 49,00 & 32 & 64,00 \\
\hline Overweight & 38 & 84,00 & 39 & 78,00 \\
\hline Smoking & 32 & 71,00 & 34 & 68,00 \\
\hline High blood pressure & 38 & 84,00 & 43 & 86,00 \\
\hline Unbalanced diet & 14 & 31,00 & 17 & 34,00 \\
\hline Excessive consumption of alcoholic beverages & 15 & 33,00 & 18 & 36,00 \\
\hline Long term effects of stress & 26 & 58,00 & 33 & 66,00 \\
\hline
\end{tabular}

$\mathrm{n}$ - frequency, $\%$ - percentage of absolute value

Another question in the questionnaire was aimed at estimating and comparing the use of vitamin preparations and over-thecounter medications. $24 \%$ of women take vitamin and nutritional supplements, while $44 \%$ of men do not use them at all. $62 \%$ of women and $40 \%$ of men use these products according to their state of health. Regular use of vitamin preparations and over-the-counter medications was admitted by $16 \%$ of male respondents and $14 \%$ of women (Table 2 ).
Table 2: Vitamin preparations and free sales drugs

\begin{tabular}{|l|c|c|c|c|}
\hline & \multicolumn{2}{|c|}{ Men } & \multicolumn{2}{c|}{ Women } \\
\hline Reply & $\mathbf{n}$ & $\mathbf{\%}$ & $\mathbf{n}$ & $\mathbf{\%}$ \\
\hline Regularly & 7 & 16,00 & 7 & 14,00 \\
\hline Health status & 18 & 40,00 & 31 & 62,00 \\
\hline $\begin{array}{l}\text { I do not use it } \\
\text { at all }\end{array}$ & 20 & 44,00 & 12 & 24,00 \\
\hline Together & $\mathbf{4 5}$ & $\mathbf{1 0 0 , 0 0}$ & $\mathbf{5 0}$ & $\mathbf{1 0 0 , 0 0}$ \\
\hline
\end{tabular}

$\mathrm{n}$ - frequency, $\%$ - percentage of absolute value

Answering the question about personal attitude towards cigarette smoking, $22 \%$ of men and $48 \%$ of women stated they do not smoke nor do they feel the need to try it. 
Table 3: Attitude to smoking cigarettes

\begin{tabular}{|l|c|c|c|c|}
\hline & \multicolumn{2}{|c|}{ Men } & \multicolumn{2}{c|}{ Women } \\
\hline Reply & $\mathbf{n}$ & $\mathbf{\%}$ & $\mathbf{n}$ & $\mathbf{\%}$ \\
\hline $\begin{array}{l}\text { I smoke 5-10 } \\
\text { cigarettes a day }\end{array}$ & 9 & 20,00 & 10 & 20,00 \\
\hline $\begin{array}{l}\text { I smoke a whole } \\
\text { pack of cigarettes } \\
\text { a day }\end{array}$ & 4 & 9,00 & 0 & 0,00 \\
\hline $\begin{array}{l}\text { I smoke but I try } \\
\text { to stop }\end{array}$ & 7 & 16,00 & 4 & 8,00 \\
\hline $\begin{array}{l}\text { I smoke 10-20 } \\
\text { cigarettes a day }\end{array}$ & 9 & 20,00 & 3 & 6,00 \\
\hline $\begin{array}{l}\text { I am smoking but } \\
\text { I've stopped }\end{array}$ & 6 & 13,00 & 9 & 18,00 \\
\hline $\begin{array}{l}\text { I do not smoke } \\
\text { and do not feel } \\
\text { the need to test it }\end{array}$ & 10 & 22,00 & 24 & 48,00 \\
\hline Together & $\mathbf{4 5}$ & $\mathbf{1 0 0 , 0 0}$ & $\mathbf{5 0}$ & $\mathbf{1 0 0 , 0 0}$ \\
\hline
\end{tabular}

$\mathrm{n}$ - frequency, $\%$ - percentage of absolute value

Consumption of alcohol was another health behavior to investigate. A positive finding is that most of the male respondents $(47.00 \%)$ and the majority of women (74.00\%) consume alcoholic beverages only occasionally, at celebrations. $20.00 \%$ of men and $8.00 \%$ of women admitted to consume alcoholic drinks just over the weekend, while $16.00 \%$ of men and $2.00 \%$ of women drink alcohol twice a week. $11.00 \%$ of men and $16.00 \%$ of women declared they do not drink alcoholic beverages at all. Women do not consume alcohol after work, whereas 3 men $(7.00 \%)$ admitted they did (Table 4$)$.

Table 4: Drinking alcoholic beverages

\begin{tabular}{|l|c|c|c|c|}
\hline & \multicolumn{2}{|c|}{ Men } & \multicolumn{2}{c|}{ Women } \\
\hline Reply & n & \% & n & \% \\
\hline $\begin{array}{l}\text { Occasionally for } \\
\text { celebrations }\end{array}$ & 21 & 47,00 & 37 & 74,00 \\
\hline Twice a week & 7 & 16,00 & 1 & 2,00 \\
\hline $\begin{array}{l}\text { I do not consume } \\
\text { alcohol at all }\end{array}$ & 5 & 11,00 & 8 & 16,00 \\
\hline $\begin{array}{l}\text { Mostly over the } \\
\text { weekend }\end{array}$ & 9 & 20,00 & 4 & 8,00 \\
\hline $\begin{array}{l}\text { Every day after } \\
\text { work }\end{array}$ & 3 & 7,00 & 0 & 0,00 \\
\hline Together & $\mathbf{4 5}$ & $\mathbf{1 0 0 , 0 0}$ & $\mathbf{5 0}$ & $\mathbf{1 0 0 , 0 0}$ \\
\hline
\end{tabular}

$\mathrm{n}$ - frequency, $\%$ - percentage of absolute value

From the statistical analysis of the collected answers to the individual questionnaire items, we find the statistically significant difference in the level of knowledge participants have about CVD risk factors, where $p=0.035$. Since this figure confirms the value of $p \leq 0.05$ it means that there is a difference in the responses between the sexes in favor of women.

Table 5: Statistical processing of data

\begin{tabular}{|c|c|c|c|c|c|}
\hline Questions from the questionnaire & n & $\mathbf{x}$ & SD & $\mathbf{t}$ & $\mathbf{p}$ \\
\hline \multirow{2}{*}{ Risk factors for cardiovascular diseases } & men 45 & 9,3 & 26,25 & \multirow{2}{*}{0,3461} & \multirow{2}{*}{0,035} \\
\hline & women 50 & 9,161 & 30,75 & & \\
\hline \multirow{2}{*}{$\begin{array}{l}\text { Use of vitamin preparations and over } \\
\text { the counter medicines }\end{array}$} & men 45 & 7 & 12,66 & \multirow{2}{*}{0,854} & \multirow{2}{*}{0,088} \\
\hline & women 50 & 15 & 16,66 & & \\
\hline \multirow{2}{*}{ Attitude to smoking cigarettes } & men 45 & 7,5 & 2,258 & \multirow{2}{*}{0,8255} & \multirow{2}{*}{0,085} \\
\hline & women 50 & 8,33 & 8,547 & & \\
\hline \multirow{2}{*}{ Drinking alcoholic beverages } & men 45 & 9 & 7,071 & \multirow{2}{*}{0,8997} & \multirow{2}{*}{0,092} \\
\hline & women 50 & 10 & 15,411 & & \\
\hline
\end{tabular}

$\mathrm{n}$ - frequency, $\mathrm{x}$ - arithmetic mean, SD - standard deviation, $\mathrm{t}$ - $\mathrm{t}$-test result, $\mathrm{p}$ - value of statistical significance 
The question related to the use of vitamin preparations and over-the-counter drugs gave us $p=0.088$, hence there is no significant difference between the responses.

Attitude of both sexes to smoking cigarettes ended up with $\mathrm{p}=0.085$. Neither did we detect any significant differences in participants' attitude to the consumption of alcoholic beverages $-\mathrm{p}=0.092$ (Table 5).

\section{Discussion}

Cardiovascular disease incidence arises from the combination of several risk factors. They develop slowly, for years, without the manifestation of subjective symptoms or warning signals. The beginnings of the current epidemic of cardiovascular disease reach back to the period of industrialization in the 18 th century. It is believed that mainly three factors account for CVD incidence: smoking, reduced physical activity, and energy-rich diet. The rapid development of cardiovascular morbidity and mortality continued to spread throughout Europe after World War II until the second half of the 20th century. In developed western countries, there was a decline in morbidity thanks to identification of the CVD risk factors in the last century. Nowadays, in the countries of Central and Eastern Europe, there are still more and more risk factors and incidence of cardiovascular disease is rising steeply.

Health protection and primordial prevention have not been given sufficient attention. According to the last Health Report on the Slovakian Population of 2009-2011, the mortality rate for cardiovascular disease decreased by $3.4 \%$ compared to $2006-2008$. Despite the positive decline of the indicators, the Slovak Republic continues to lag behind in the state of health of Western European populations. There is a high incidence of risk factors in the population (hypertension, obesity, smoking, etc.). Professor Rovny, the former Principal Hygienist of the Slovak Republic in his 2012 Statement on the Health of the Slovak Population states that the incidence of circulatory system diseases in women is $13.9 \%$ higher than in men, but the average life expectancy of women is 8.72 years higher compared to men.

Strategic disease prevention and health promotion are the only ways out of the current unfavorable situations regarding the population's state of health. Knowledge of the state of health of the population enables us to set priorities in planning preventive measures. Living a healthy lifestyle is often perceived as a number of prohibitions and limitations. It is necessary to change this point of view; to think of life as the highest value; to understand the need for change. To be concerned with one's own health and to acquire new habits and integrate new health behaviors and manners can be really creative and encouraging. With strong will, we can establish the foundation of new lifestyle and identify with it. Our life can be pleasant; satisfying; at the same time inspiring for others. Nowadays, the public is overwhelmed by a lot of information from the media about how to prevent disease, but this information is often full of contradictions. There is a need to recognize trustworthy information. During different kinds of public events people often show an interest in broadening their knowledge of risk factors which threaten their health (1-3).

The main objective of this study was to assess and compare men and women's adherence to healthy lifestyle and their knowledge of well-being. By examining the outcome of the survey, we found that female respondents are more aware of CVD risk factors than male participants. Women expressed bigger satisfaction with the care for their own health than men. The regular use of vitamin preparations and over-the-counter medications is preferred by men, but many do not use them at all, whereas the 
vast majority of women take vitamin preparations and over-the-counter medications as needed. When we look at the attitude of both sexes toward smoking, we can say that most women either do not smoke or smoke 5-10 cigarettes a day, while men usually smoke 5-20 cigarettes daily or their try to get rid of this addiction. Females consume alcohol only occasionally when celebrating or not at all. Most men drink alcoholic beverages occasionally, over a weekend or twice a week. It is a paradox that even though men are able to name smoking and alcohol consumption as CVD risk factors, they are attracted to them more than women. Women's conscious attitude towards health probably stems from their maternal responsibility and the responsibility for bringing a healthy generation. Evaluating the results, we can conclude that female participants are more interested in healthy lifestyle and live a healthier life than male participants.

In Slovakia, the percentage of smokers is $20.1 \%$ (of which $24.6 \%$ are men and $17.6 \%$ are women). The situation in younger age groups is unfavorable and in the groups with higher levels of education the situation is more favorable. In terms of smoking, the survey showed similar results for both sexes. On average, $32.5 \%$ of men and $17 \%$ of women smoke.
Despite the high average alcohol consumption in Slovakia and all of the above statistics, our volunteers admitted only very low alcohol consumption: a large majority do not consume alcoholic beverages at all or only rarely; only $1.5 \%$ of people consume spirits; $1.4 \%$ wine; $4.7 \%$ (2) beer daily or almost daily.

\section{Conclusion}

The most important precondition for balanced life is a sound health, which is the basis of life and a fundamental human right. Looking after one's own health should be the priority of each individual and the society.

\section{References}

1. ARMAIOVA M (2017) Healthy lifestyle and its importance in the prevention of cardiovascular diseases of the manager: diploma thesis. Bratislava: St. Elisabeth University of Health and Social Sciences, 2017. 52 p.

2. JURKOVICOVA J (2005) Do we live healthy? Bratislava: UK 2005166 p ISBN 80-223-2132-X.

3. CERVENANOVA E (2012) Lifestyle. In Revue Medicine in Practice. ISSN: 1336202X, 2012, p. 19-20. 